\title{
Key Intermediates for Introducing a Bulky Bicyclo[3.3.0]heptane Skeleton in the w-Side Chain to Reduce the Enzyme Inactivation of Prostaglandins ${ }^{t, \ddagger}$
}

\author{
Constantin Tănase ${ }^{1, *}$, Constantin Drăghici ${ }^{2}$ and Miron Theodir Căproiu ${ }^{2}$ \\ 1 National Institute for Chemical-Pharmaceutical Research and Development, 112 Vitan Av., 031299 \\ Bucharest-3, Romania \\ 2 Organic Chemistry Center “C.D.Nenitescu”, 202 B Splaiul Independentei, 060023 Bucharest, Romania; \\ cst_drag@yahoo.com (C.D.); dorucaproiu@gmail.com (M.T.C.) \\ * Correspondence: cvtanasel@gmail.com \\ + Presented at the 24th International Electronic Conference on Synthetic Organic Chemistry, 15 November-15 \\ December 2020; Available online: https://ecsoc-24.sciforum.net/. \\ $\ddagger$ In meantime the manuscript was accepted to be published in New J. Chem. 2020, DOI:10.1039/D0NJ04594B. \\ Published: date
}

\begin{abstract}
In vivo, the prostaglandins (PGs) are inactivated by enzyme oxidation of the $15-\alpha-\mathrm{OH}$ group to 15-keto group. 15-, 16-Substituents, 16-Aryloxy and others diminished this inactivation [1]. We planed to diminish inactivation by introducing bulky bicyclo[3.3.0]octane or bicyclo[3.3.0]oct-6-ene substituents linked to the C-15 carbon atom, but also to introduce this fragment found in nature and in compounds with anticancer activity. $\omega$-Side chain of PGs are introduced by an E-HEW-stereoselective olefination of an aldehyde with a $\beta$-ketophosphonate (Corey procedure). The $\beta$-ketophosphonates were synthesized from bicyclo[3.3.0]oct(a)ene acids by a two or three step sequence in good yields and used for obtaining a new PG.
\end{abstract}

Keywords: $\quad \beta$-ketophosphonate; $\quad$ prostaglandin analogs; bicyclo[3.3.0]octane; bicyclo[3.3.0]oct-6-ene; pseudo-prostaglandin

\section{Introduction}

The inactivation of the prostaglandins (PGs) by enzyme oxidation of $15 \alpha-\mathrm{OH}$ to the 15 -keto group via the 15-PGDH pathway was diminished by introduction of 15-methyl, 16-dimethyl, difluoro, methyl and OMe, cyclohexyl, cyclopentyl, phenyl or 16-aryloxy groups. In the same time the modifications in the $\omega$-side chain were most beneficial for biologic activity of the compounds [1,2]. In this direction we planed to introduce a bicyclo[3.3.0]oct(a)ene fragment linked to the $\mathrm{C}_{15}$ carbon atom to introduce a more hindered access of the enzyme to the 15-hydroxyl group. We also took into account the fact that a bicyclo[3.3.0]octane fragment is found in the molecule of recognized drugs like (iso)carbacyclins and their analogs and also in the molecule of many natural products, some of them with antitumor activity [3]. So this fragment could give interesting biological activities to the new PGs analogs. This concept for the $\omega$-side chain of these new PGs analogs is design in the $\beta$-ketophosphonates used in an E-HEW stereoselective olefination with a cyclopentane aldehyde. The paper presents the synthesis of new $\beta$-ketophosphonates which contain a bicyclo[3.3.0]octane or a bicyclo[3.3.0]oct-6-ne scafold in the molecule linked to the ketone group.

For papers that report original research, you should use the titles "Materials and Methods", "Results", “Discussion" and "Conclusions" (optional). 


\section{Results}

New $\beta$-ketophosphonates with a bicyclo[3.3.0]octane or bicyclo[3.3.0]oct-6-ene fragment were synthesized starting from the diacids 1 in a sequence of 2 to 4 high yield steps (Scheme 1):
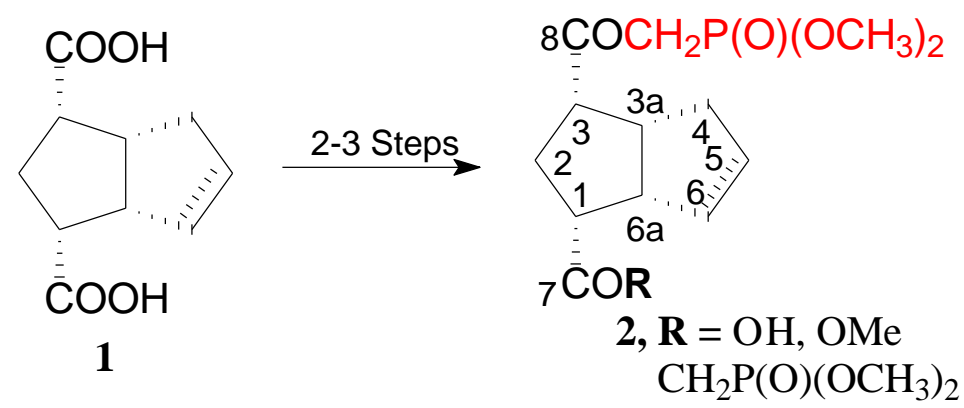

Scheme 1. Synthesis of $\beta$-ketophosphonates 2 starting from diacids 1 .

In a sequence, the diacids [4] were transformed in the anhydrides [5] which, by reaction of the lithium salt of dimethyl methanephosphonate (DMMPh) (generated in situ from DMMPh and $\mathrm{n}$-BuLi in and. THF at low temperature (below $\left.-70^{\circ} \mathrm{C}\right)$ ), gave the $\beta$-ketophosphonates $2(\mathrm{R}=\mathrm{OH})$. Then the diacids were cleanly transformed in the methyl esters by reaction with diazomethane in diethyl ether-chloroform.

In another sequence, the diacids were esterified $(\mathrm{MeOH} / \mathrm{TsOH}, \mathrm{rt})$ and the diesters were reacted with the lithium salt of DMMPh, in the same conditions, to give the $\beta$-ketophosphonates $2(R=$ $\mathrm{OMe})$, toghether with a quantity of bis- $\beta$-ketophosphonates $2\left(\mathrm{R}=\mathrm{CH}_{2} \mathrm{P}(\mathrm{O})(\mathrm{OMe})_{2}\right)$, depending of the ratio of DMMPh/diester. For ex. in the case of saturated bicyclo[3.3.0]octane phosphonates, at a ratio of 2.05:1 $\mathrm{DMMPh} /$ diester, mono $\beta$-ketophosphonates was obtained in $33.5 \%$ and bis$\beta$-ketophosphonates in $31.8 \%$. At greater ratio of $\mathrm{DMPh} /$ diester, a greater amount of bisphosphonate 12 was obtained. The saturated $\beta$-ketophosphonates $2(\mathrm{R}=\mathrm{OMe})$ was used in an E-HEW stereoselective olefination with the aldehyde intermediate 4 with $\alpha$-side chain, obtained by transacetalization of the intermediate 3, to give the new PG analog 5 with the bicyclo[3.3.0]octane linked to $\mathrm{C}_{15}$ carbon atom (Scheme 2 ) in $73 \%$ yield:

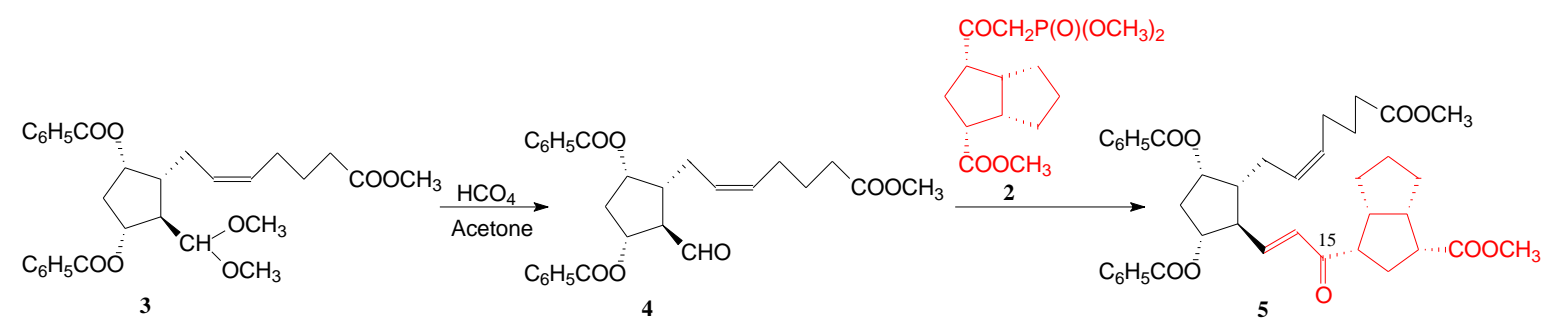

Scheme 2. Sinthesis of new PG analogs with a bicyclo[3.3.0]octane linked to $\mathrm{C}_{15}$ carbon atom.

The reduction of the 15-keto group with a bulky reducing reagent, like aluminium diisobornyloxyisopropoxyde, gave no 15-allylic alcohol, this demonstrating that also the access of the enzymes will be restricted by the bulky the bicyclo[3.3.0]octane fragment. The use of of bis- $\beta$-ketophosphonates $2\left(\mathrm{R}=\mathrm{CH}_{2} \mathrm{P}(\mathrm{O})(\mathrm{OMe})_{2}\right)$, in the E-HEW stereoselective olefination of the aldehyde intermediate $\mathbf{4}$ will give to a pseudo-PG analog with formula I, 


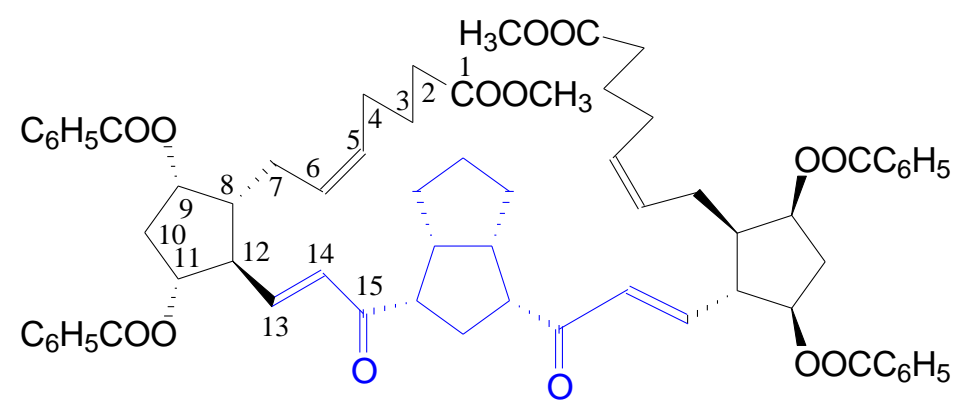

\section{I, 15-keto-pseudo-Prostaglandin analogue}

Figure 1. Keto-pseudo-prostaglandin analogue I should be obtained with bis- $\beta$-ketophosphonate 2 ( $R$ $\left.=\mathrm{CH}_{2} \mathrm{P}(\mathrm{O})(\mathrm{OMe})_{2}\right)$.

In conclusion, mono- $\beta$-ketophosphonates and bis- $\beta$-ketophosphonates 2 were synthesized and a PG analog with a bulky bicyclo[3.3.0]octane in the $\omega$-side chain was synthesized.

In meantime, the work presnted above, was included in an manuscript which was accepted to be published in New J. Chem. 2020, DOI:10.1039/D0NJ04594B [6]

\section{Patents}

A patent was deposited to OSIM - Romania with the no. C. Tănase, M.T. Căproiu, C. Drăghici, A/00517/14.08.2020.

Author Contributions: Conceptualization, C.T.; Synthesis of the compounds, C.T; NMR analysis of the compounds, C.D. and M.T.C.; writing-original draft preparation, all authors. All authors have read and agreed to the published version of the manuscript.

Funding: This research was funded by Ministry of Education and Research for the grant Orizont-2000, 45/1999/1.

Conflicts of Interest: The authors declare no conflict of interest.

\section{References}

1. Collins, P.W.; Djuric, S.W. Synthesis of therapeutically useful prostaglandin analogs. Chem. Rev. 1993, 93, 1533-1564.

2. Peng, H.; Chen, F.-E. Recent advances in asymmetric total synthesis of prostaglandins. Org. Biomol. Chem. 2017, 15, 6281-6301.

3. Tănase, C.; Drăghici, C.; Shova, S.; Maganu, M.; Cojocaru, A.; Munteanu, C.V.A.; Cocu, F. Regioselective reactions on a 1,3-disubstituted dihydroxymethyl or dicarboxyl hexahydropentalene skeleton. Tetrahedron 2015, 71, 6852-6859.

4. Tolstikov, G.A.; Miftakov, M.S.; Danilova, N.A.; Sitikova, O.V. Zhur. Org. Khim. 1985, XXI, 675-676.

5. Starck, G.P.; Golobish, T.D.; Aboud-Gharbia, M.A.-M. Psychotropic Polyciclic Imides. EP 0286263/1988.

6. Tănase, C.; Drăghici, C.; Căproiu, M.T. New $\beta$-ketophosphonatesfor the synthesis of prostaglandin analogues. 2. Phosphonates with a bicyclo[3.3.0]octene and bicyclo[3.3.0]octane scaffolds linked to the $\beta$-ketonegroup. New J. Chem. 2020, NJ-ART-09-2020-004594.R1, doi:10.1039/D0NJ04594B.

7. Tănase, C.; Căproiu, M.T.; Drăghici, C. $\beta$-Ketophosphonates with a hexahydro- and octahydropentalene functionaalyzed fragment for obtaining new prostaglandin analogs. A/00517/14.08.2020.

Publisher's Note: MDPI stays neutral with regard to jurisdictional claims in published maps and institutional affiliations.

(C) 2020 by the authors. Submitted for possible open access publication under the terms and conditions of the Creative Commons Attribution (CC BY) license (http://creativecommons.org/licenses/by/4.0/). 